\title{
Adsorption Mechanisms of Thallium by Soils
}

\author{
SHAN-LI WANG ${ }^{1^{*}}$, HONG-YUN LIN ${ }^{2}$, LING-YI KUO $^{3}$ AND
} PUU-TAI YANG ${ }^{4}$

${ }^{1}$ Department of Agricultural Chemistry, National Taiwan University, Taipei 10617, Taiwan $\left({ }^{*}\right.$ correspondence: wangsl@ntu.edu.tw)

${ }^{2}$ Department of Agricultural Chemistry, National Taiwan University, Taipei 10617, Taiwan (irislin314@gmail.com)

${ }^{3}$ Department of Agricultural Chemistry, National Taiwan University, Taipei 10617, Taiwan (lyguo@tari.gov.tw)

${ }^{4}$ Department of Agricultural Chemistry, National Taiwan University, Taipei 10617, Taiwan (d07623001@ntu.edu.tw)

Thallium (Tl) is highly toxic, but its fate in soil has not been well understood. This study investigated the adsorption mechanisms of $\mathrm{Tl}(\mathrm{I})$ by soils, which have different mineralogical and physicochemical properties. The adsorption and desorption isotherms of Tl(I) were determined for six soil samples and various soil components, including vermiculite, illite, montmorillonite, beidellite, goethite and humic acid. The clay minerals, vermiculite, illite and smectite, had predominant contributions to the overall $\mathrm{Tl}(\mathrm{I})$ adsorption of the soils, while the contributions from other soil colloids were relatively minor. The X-ray absorption spectroscopic results of Tl(I) adsorbed on soil components revealed that the adsorption of Tl(I) of vermiculite and illite were both specific, while those of other soil components were non-specific. The adsorption/desorption isotherms of each soil were both fitted to Freundlich equation and the results were subsequently used to calculate the hysteresis coefficient. The adsorption/desorption of $\mathrm{Tl}(\mathrm{I})$ by soils was partially irreversible, depending on the types of clay minerals and exchangeable cations in the soils. The adsorption hysteresis of $\mathrm{Tl}(\mathrm{I})$ by soils was mainly attributed to the presences of vermiculite and illite in the soils. Accordingly, $\mathrm{Tl}(\mathrm{I})$ is expected to be leached in soils, indicating the environmental risk of $\mathrm{Tl}(\mathrm{I})$ pollution in soils. With the presences of vermiculite and illite, the retentions of $\mathrm{Tl}(\mathrm{I})$ by these minerals can lower the environmental risk of $\mathrm{Tl}(\mathrm{I})$ pollution in soils. 